Foundations of Communication Library Edition

Editors

Roland Posner and Georg Meggle 



\section{On Believing}

Epistemological and Semiotic Approaches

\section{De la croyance}

Approches épistémologiques et sémiotiques

Edited by / Textes présentés par

Herman Parret

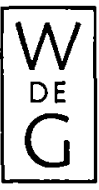

Walter de Gruyter - Berlin - New York 1983 
On believing : epistemolog. and semiot. approaches - De la croyance / ed. by Herman Parret. - Berlin ; New York : de Gruyter, 1983.

(Foundations of communication : Libr. ed.)

ISBN 3-11-008884-3

NE: Parret, Herman [Hrsg.]; PT

\section{Library of Congress Cataloging in Publication Data}

Main entry under title:

On believing.

(Foundations of communication)

Bibliography: $p$.

Includes index.

1. Belief and doubt-Addresses, essays, lectures.

I. Parret, Herman. II. Title: De la croyance. III. Series.

BD215.06 1983

$121^{\prime} .6$

ISBN 3-11-008884-3 (lib. bdg.)

(C) Copyright 1983 by Walter de Gruyter \& Co., vormals G. J. Göschen'sche Verlagshandlung - J. Guttentag, Verlagsbuchhandlung - Georg Reimer - Karl J. Trübner Veit \& Comp., Berlin 30. Printed in Germany.

Alle Rechte des Nachdrucks, der photomechanischen Wiedergabe, der Herstellung von Photokopien - auch auszugsweise - vorbehalten.

Satz und Druck: Arthur Collignon GmbH, Berlin

Buchbinder: Lüderitz \& Bauer, Berlin 